\title{
Probes for the study of mupirocin resistance in staphylococci
}

\author{
M. RAHMAN*, W. C. NOBLE* $\ddagger$ and K. G. H. DYKE $\dagger$ \\ * Department of Microbial Diseases, St John's Institute of Dermatology, St Thomas' Hospital, London SE1 7EH and \\ $\uparrow$ Microbiology Unit, Biochemistry Department, University of Oxford, South Parks Road, Oxford OX1 $3 Q U$
}

\begin{abstract}
Summary. Probes constructed from a 4.05-kb EcoRI digest fragment of a mupirocin resistance plasmid and a 751-bp internal part of this fragment hybridised with DNA from all of 36 independent high-level mupirocin-resistant staphylococci tested from seven centres; most were Staphylococcus aureus. In most instances the probes detected an EcoRI digest fragment of approximately $4 \mathrm{~kb}$. Probes did not hybridise to DNA from low-level resistant strains, nor from strains sensitive to mupirocin.
\end{abstract}

\section{Introduction}

Mupirocin (SmithKline Beecham) is a relatively new topical antibiotic with a novel antibacterial activity; it inhibits the isoleucyl tRNA synthetase of staphylococci and streptococci, a mechanism not possessed by other commercially available antibiotics. High-level resistance to mupirocin (MIC > $2000 \mathrm{mg} / \mathrm{L}$ ) was first described in $1987 .^{1,2}$ It has been shown recently that strains exhibiting high-level resistance possess two isoleucyl tRNA synthetases, one of which is not inhibited by mupirocin. ${ }^{3}$ Resistance determinants were found to be carried on a diversity of plasmids as judged by EcoRI and HindIII restriction fragment patterns; only some plasmids were easily transferred and some plasmids could be demonstrated only by pulsed-field gel electrophoresis. ${ }^{4}$ In 1991, Dyke et al. ${ }^{5}$ cloned a mupirocin-resistance gene in Escherichia coli as a 4.05-kb Eco RI digestion fragment from a staphylococcal plasmid in strain 5 of Rahman et $a l^{4}$ Here, the use of this fragment and of a smaller internal piece of it as probes for mupirocin resistance is reported.

\section{Materials and methods}

\section{Bacterial isolates}

The list of resistant staphylococci studied is shown in the table. These comprised chiefly strains isolated from patients attending the inpatient wards or outpatient clinics of the St John's Dermatology Centre and were judged to be independent on epidemiological data as well as antibiogram and plasmid profile (data not shown). Three sets of strains are described: (a) strains exhibiting high-level resistance (MIC >

Received 11 Feb. 1993; accepted 21 May 1993.

$\ddagger$ Correspondence should be sent to Professor W. C. Noble.
$2000 \mathrm{mg} / \mathrm{L}$ ) and recognised initially by their ability to grow up to a disk containing mupirocin $200 \mu \mathrm{g}$; (b) low-level resistant strains (MIC 5-50 mg/L) that may grow close to a $5-\mu \mathrm{g}$ disk but not a $200-\mu \mathrm{g}$ disk; (c) mixed strains that exhibited a small number of resistant colonies in the zone around a 200- $\mu \mathrm{g}$ disk. In addition, 12 independent wholly sensitive Staphylococcus aureus strains were examined (epidemiological details not shown). Three strains of coagulasenegative staphylococci (nos. 19-21) reported previously ${ }^{4}$ have been studied in more detail and are reported separately. ${ }^{6}$

\section{Probe construction}

Antibiotic resistance patterns and plasmid profiles of the original strains were determined as described previously and, where possible, the mupirocin resistance plasmid was transferred to a standard strain by filter mating. ${ }^{4}$ DNA was prepared from staphylococci as described previously and from $E$. coli by the SDS method. ${ }^{7}$ Restriction enzymes were purchased from Gibco BRL (Paisley) and were used according to the manufacturer's instructions. Restriction fragment length patterns were prepared with transconjugant plasmid DNA from caesium chloride-ethidium bromide density gradients or from a plasmid preparation of the original strain as described previously. ${ }^{4}$ Standards were $E$. coli strain V517 for intact plasmids or phage $\lambda$ DNA cut by HindIII (Gibco BRL) for fragments.

Probes were constructed from the 4.05-kb EcoRI fragment described by Dyke et al. ${ }^{5}$ cloned in E. coli and a 751-bp XhoI/BgIII piece from within the 1.6-kb $N c o$ I fragment of the gene.

Transfer of EcoRI digest fragments on to Flash Nylon membrane (Stratagene, Cambridge) was by standard methods. ${ }^{7}$ Probe DNA was recovered from agarose gels with the Geneclean II kit (Stratech, Luton, 
Table. Characteristics of resistant strains studied

\begin{tabular}{|c|c|c|c|c|c|c|c|}
\hline $\begin{array}{l}\text { Strain } \\
\text { no. }\end{array}$ & Source & $\begin{array}{l}\text { Year } \\
\text { of isolation }\end{array}$ & Species & $\begin{array}{l}\text { Resistance* } \\
\text { patterns }\end{array}$ & $\begin{array}{l}\text { Plasmid } \\
\text { profile } \dagger\end{array}$ & $\begin{array}{l}\text { Mupirocin } \\
\text { MIC (mg/L) }\end{array}$ & $\begin{array}{c}\text { Resistance } \\
\text { transferred to } \\
\text { standard recipient }\end{array}$ \\
\hline 1. & STH & 1987 & S. aureus & Pc, Tc, Em & $30,4 \cdot 2,3 \cdot 4,3 \cdot 1,2 \cdot 7,2 \cdot 2$ & $>2000$ & + \\
\hline 2. & Glasgow & 1987 & S. aureus & $\mathrm{Pc}, \mathrm{Tc}, \mathrm{Em}$ & $30,4 \cdot 2$ & $>2000$ & + \\
\hline 3. & Bristol & 1987 & S. aureus & $\mathrm{Pc}$ & $50,30,2 \cdot 9,2 \cdot 3$ & $>2000$ & + \\
\hline 4. & STH & 1988 & S. aureus & $\mathrm{Pc}$ & 35,20 & $>2000$ & + \\
\hline 5. & STH & 1988 & S. aureus & $\mathrm{Pc}$ & 35,25 & $>2000$ & + \\
\hline 6. & Warr & 1988 & S. aureus & $\begin{array}{l}\mathrm{Pc}, \mathrm{Tc}, \mathrm{Em}, \mathrm{Cl}, \mathrm{Nm} \\
\mathrm{Gm}, \mathrm{Mt}\end{array}$ & $50,35,3 \cdot 5$ & $>2000$ & + \\
\hline 7. & Warr & 1988 & S. aureus & $\begin{array}{l}\mathrm{Pc}, \mathrm{Tc}, \mathrm{Em}, \mathrm{Cl}, \mathrm{Nm} \\
\mathrm{Gm}, \mathrm{Mt}\end{array}$ & $35,3 \cdot 5$ & $>2000$ & + \\
\hline 8. & STH & 1989 & S. aureus & $\mathrm{Pc}, \mathrm{Tc}, \mathrm{Em}, \mathrm{Nm}$ & $30,2 \cdot 8$ & $>2000$ & + \\
\hline 9. & STH & 1989 & S. aureus & Sensitive & 35 & $>2000$ & - \\
\hline 10. & STH & 1989 & S. aureus & Sensitive & 35 & $>2000$ & - \\
\hline 11. & Nigeria & 1965 & S. aureus & Pc & $20,15,6.5$ & $>2000$ & - \\
\hline 12. & Nigeria & 1965 & S. aureus & $\mathrm{Pc}$ & $20,15,6.5$ & $>2000$ & - \\
\hline 13. & Nigeria & 1965 & S. aureus & $\mathrm{Pc}$ & 25,20 & $>2000$ & + \\
\hline 14. & STH & 1987 & S. epidermidis & Pc, Tc, Em & $30,25,5 \cdot 9,5 \cdot 0,2 \cdot 9$ & $>2000$ & + \\
\hline 15. & STH & 1987 & S. epidermidis & $\mathrm{Pc}, \mathrm{Tc}, \mathrm{Em}$ & $35,4 \cdot 2,2 \cdot 9$ & $>2000$ & - \\
\hline 16. & STH & 1987 & S. epidermidis & $\mathrm{Pc}, \mathrm{Tc}, \mathrm{Em}$ & $30,6 \cdot 5,4 \cdot 0,2 \cdot 6$ & $>2000$ & + \\
\hline 17. & STH & 1987 & S. epidermidis & $\mathrm{Pc}, \mathrm{Tc}$ & $>56,4 \cdot 3$ & $>2000$ & - \\
\hline 18. & Nigeria & 1965 & S. epidermidis & Sensitive & $25,3 \cdot 2,2 \cdot 5$ & $>2000$ & + \\
\hline 22. & STH & 1990 & S. aureus & Pc, Em & $2 \cdot 8$ & $>2000$ & + \\
\hline 23. & STH & 1990 & S. aureus & $\mathrm{Pc}$ & 47 & $>2000$ & - \\
\hline 24. & STH & 1990 & S. aureus & $\mathrm{Pc}$ & 47,26 & $>2000$ & - \\
\hline 25. & STH & 1990 & S. aureus & Pc, Tc & $\begin{array}{l}44,17,7,4 \cdot 8, \text { and } \\
2 \text { less than } 1.5 \mathrm{~kb}\end{array}$ & $>2000$ & + \\
\hline 26. & STH & 1990 & S. aureus & Pc & $>56,21$ & $>2000$ & - \\
\hline 27. & STH & 1990 & S. aureus & $\mathrm{Tc}$ & $56,6 \cdot 3$ & $>2000$ & - \\
\hline 28. & STH & 1990 & S. aureus & $\mathrm{Pc}, \mathrm{Tc}$ & $56,4 \cdot 4,1 \cdot 8$ & $>2000$ & + \\
\hline 29. & STH & 1990 & S. aureus & Pc, Tc & $\begin{array}{l}35,6 \cdot 3,4.4 \text { and } \\
2 \text { smaller than } 1.5 \mathrm{~kb}\end{array}$ & $>2000$ & + \\
\hline 30. & STH & 1990 & S. aureus & $\mathrm{Pc}, \mathrm{Tc}, \mathrm{Em}$ & $37,4 \cdot 0,3 \cdot 1,2 \cdot 8$ & $>2000$ & + \\
\hline 31. & Warr & 1988 & S. aureus & $\mathrm{Pc}, \mathrm{Tc}, \mathrm{Em}, \mathrm{Cl}, \mathrm{Nm}, \mathrm{Gm}$ & $>56,56$ & $>2000$ & - \\
\hline $32 \mathrm{a}$. & STH & 1990 & S. aureus & $\mathrm{Em}$ & $56,22,3 \cdot 1,2 \cdot 5$ & 5 & - \\
\hline $32 \mathrm{~b}$. & & & S. aureus & Sensitive & None seen & $>2000$ & + \\
\hline $33 a$. & S.end & 1990 & S. aureus & $\mathrm{Pc}, \mathrm{Tc}, \mathrm{Em}, \mathrm{Gm}, \mathrm{Mt}$ & $20 \cdot 4$ & $<5$ & - \\
\hline 33b. & & & S. aureus & $\mathrm{Pc}$ & 56 & $>2000$ & - \\
\hline $34 a$. & STH & 1990 & S. aureus & $\mathrm{Pc}$ & $24 \cdot 6,6 \cdot 2$ & 5 & - \\
\hline $34 \mathrm{~b}$. & & & S. aureus & $\mathrm{Pc}$ & 56 & $>2000$ & - \\
\hline 35a. & STH & 1988 & $S$. aureus & $\mathrm{Pc}, \mathrm{Tc}, \mathrm{Em}$ & $19 \cdot 5,4 \cdot 6,2 \cdot 5$ & 10 & - \\
\hline $35 \mathrm{~b}$. & & & S. aureus & $\mathrm{Pc}$ & 56 & $>2000$ & - \\
\hline $36 a$. & W.X. & 1988 & S. aureus & $\mathrm{Pc}, \mathrm{Tc}, \mathrm{Em}$ & $6 \cdot 5,<2 \cdot 2$ & 10 & - \\
\hline $36 \mathrm{~b}$. & & & S. aureus & Pc & 56 & $>2000$ & - \\
\hline 37. & STH & 1990 & S. aureus & Sensitive & $>56,19 \cdot 5,3 \cdot 3,2 \cdot 6$ & 10 & - \\
\hline 38. & STH & 1990 & S. aureus & $\mathrm{Pc}$ & $>56$ & $<5$ & - \\
\hline 39. & STH & 1990 & S. aureus & $\mathrm{Pc}, \mathrm{Tc}, \mathrm{Em}$ & $>56,15 \cdot 5,4 \cdot 3,3 \cdot 5,2 \cdot 6$ & $10-40$ & - \\
\hline
\end{tabular}

STH, St John's Dermatology Centre, St Thomas' Hospital; Warr, Warrington; W.X., Whipps Cross, London; S.end, Southend, Essex. Nos 1-18 have been described previously and the EcoRI digests of the mupirocin plasmids have been determined.

Nos 19-21 have now been studied in greater detail and are included in a separate report.

Nos $28-30$ possessed a very similar mupirocin plasmid.

No. 39 represents eight isolates tested from eight different inpatients over a period of 10 months in an apparent episode of cross-infection. Mixed strains are indicated by a and $b$ (nos 32-36).

* Resistances examined were penicillin (Pc), tetracycline (Tc), erythromycin (Em), clindamycin (Cl), neomycin (Nm), gentamicin $(\mathrm{Gm})$ and methicillin (Mt) in addition to mupirocin.

$\uparrow$ Measured as intact plasmids in agarose gels.

Beds) and was labelled with the "Flash" Prime-It Random Labelling kit (Stratagene) according to the manufacturer's instructions. Biotinylated DNA was detected on membranes by the Flash Detection System (Stratagene) according to the manufacturer's instructions. Biotinylated $\lambda$ DNA cut by HindIII (Gibco BRL) was used as a standard.

\section{Results}

Most of the original strains were epidemiologically independent as judged by antibiotic resistance patterns and plasmid profiles (table) although some yielded mupirocin resistance plasmids with similar structures. Many of these mupirocin resistance plasmids were transferable to standard recipient strains and six new profiles were added (data not shown). The strains numbered 32-36 (Group C) were originally recorded as having low-level resistance but colonies grew within the inhibition zones to yield resistant variants. When these were subcultured they proved to have a different antibiotic resistance pattern from the low-level strains and four of the five strains (nos 33-36) carried plasmids with the same EcoRI digest pattern. 


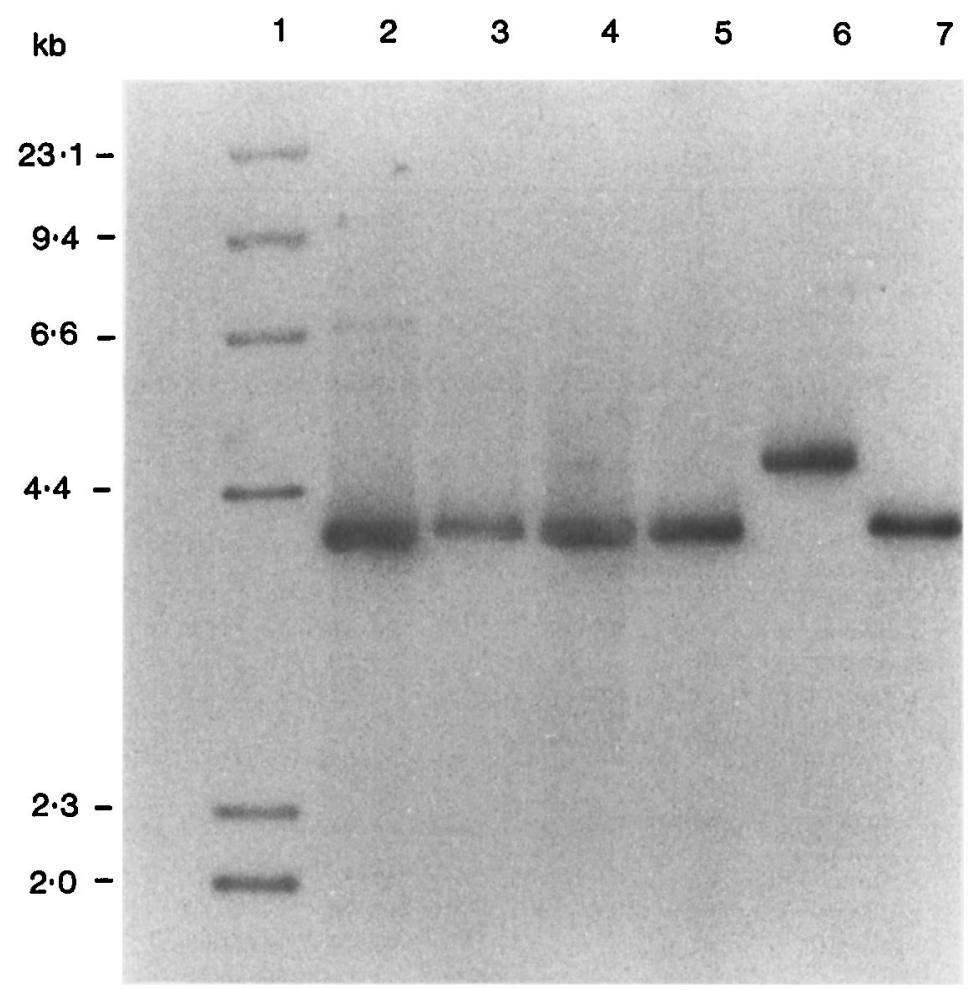

Figure. Hybridisation of $4.05-\mathrm{kb}$ probe to $E c o$ RI digests of transferred plasmids or whole cell digests. Lane 1, $\lambda$ phage digests with $H$ indIII; 2 , strain $27 ; 3$, strain $23 ; 4$, strain $24 ; 5$, strain $5 ; 6$, strain $8 ; 7$, strain 31 . Strain numbers refer to the table.

In most instances, both probes hybridised to a $c$. 4$\mathrm{kb} E c o$ RI restriction fragment. The exceptions were strain 1 which hybridised to a fragment of $c .18 \mathrm{~kb}$ (it has proved possible to separate the former large fragment into two, one of $18 \mathrm{~kb}$ and the other of $c$. $25 \mathrm{~kb})$ and strain 8 which hybridised to a fragment of c. $4.8 \mathrm{~kb}$ (figure). Other DNA fragments did not hybridise to the probes. Neither probe hybridised to DNA from the low-level resistant strains nor from the fully sensitive strains.

\section{Discussion}

The addition of a further 10 apparently distinct high-level resistant strains to our previous 21 , which yielded a further six distinct EcoRI restriction fragment patterns from the eight plasmids transferred or seen as single plasmids (nos. 32-36), confirms our previous observations ${ }^{4}$ on the diversity of plasmids which carry this resistance determinant.

The results with the $4 \cdot 05-\mathrm{kb}$ and $751-\mathrm{bp}$ probes were identical. The probes revealed a single fragment in all high-level resistant strains corresponding in most cases to the 4.05-kb EcoRI fragment described from strain 5 in this series by Dyke et al. ${ }^{5}$ DNA from low-level resistant strains, which can be assumed to be similar to those obtained originally by serial culture on agar containing mupirocin, ${ }^{8}$ did not hybridise to the probe, indicating a different mechanism of resistance. This has recently been confirmed by the report of two isoleucyl tRNA synthetases in mupirocin-resistant $S$. aureus. ${ }^{3}$

Five strains (nos. 32-36), which were apparently epidemiologically independent, were initially described as low-level resistant strains but were later observed to have a few colonies growing around the mupirocin disk during testing. On subculture, these proved to be high-level resistant strains with a different resistance pattern to the low-level "parent" strains. Four of these (nos. 33-36) possessed an indistinguishable resistance plasmid. There is no immediate explanation for this; laboratory cross-contamination cannot be excluded but the plasmid structure was not one that had been encountered previously. However, it is worth noting that co-existent high- and low-level resistant strains have been encountered previously. ${ }^{4}$

The almost constant size of the EcoRI fragment which hybridised with the probe suggests that the same genetic element is involved in all resistant strains; this is also true of the coagulase-negative staphylococci reported in detail by Connolly et al.$^{6}$ If this is true, it may prove possible to modify the antibiotic in such a way as to inhibit this particular gene and thus eliminate or reduce the prevalence of resistance.

We are grateful to those who sent us strains from outside St Thomas' Hospital. This work was supported by a grant from SmithKline Beecham, to whom we are grateful. 


\section{References}

1. Rahman M, Noble WC, Cookson B. Mupirocin-resistant Staphylococcus aureus. Lancet 1987; 2: 387.

2. Rahman M, Noble WC, Cookson B. Transmissible mupirocin resistance in Staphylococcus aureus. Epidemiol Infect 1989; 102: $261-270$.

3. Gilbart J, Perry CR, Slocombe B. High level mupirocin resistance in Staphylococcus aureus: evidence for two distinct isoleucyl-tRNA synthetases. Antimicrob Agents Chemother 1993; 37: 32-38.

4. Rahman M, Connolly S, Noble WC, Cookson B, Phillips I. Diversity of staphylococci exhibiting high level resistance to mupirocin. J Med Microbiol 1990; 33: 97-100.
5. Dyke KGH, Curnock SP, Golding M, Noble WC. Cloning of the gene conferring resistance to mupirocin in Staphylococcus aureus. FEMS Microbiol Lett 1991 ; 61 : 195-198.

6. Connolly S, Noble WC, Phillips I. Mupirocin resistance in coagulase-negative staphylococci. J Med Microbiol 1993; 39: $450-453$.

7. Sambrook J, Fritsch EF, Maniatis T. Molecular cloning--A laboratory manual, 2nd edn. Cold Spring Harbor, NY, Cold Spring Harbor Laboratory Press. 1989: 38-41.

8. Casewell M, Hill RLR. The laboratory assessment of the antistaphylococcal activity of mupirocin. In: Mupirocin : a novel topical antibiotic. Royal Society of Medicine. 1984: $57-64$. 